\title{
A psychological perspective on virtual communities supporting terrorist \& extremist ideologies as a tool for recruitment
}

\author{
Lorraine Bowman-Grieve
}

\begin{abstract}
This paper considers the role of virtual communities as a tool for recruitment used by terrorist and extremist movements. Considering involvement as a psychological process and thinking about recruitment from a psychological perspective, the facilitation of online elements important to this process are highlighted in this paper. In addition a short case study taken from the use of the Internet by the Radical Right movement provides examples of how the Internet can be used to promote involvement and encourage recruitment into terrorist and extremist movements.
\end{abstract}

Keywords: Psychology, Terrorism, Extremism, Virtual communities, Recruitment

\section{Background}

Understanding terrorism: a group phenomenon

Terrorism is, first and foremost, a group phenomenon [1], the dynamics of which have traditionally been difficult to assess due to the predominantly clandestine nature of these organisations. However, the Internet and its use by terrorist movements, individual members, and potential supporters and recruits afford new avenues for accessing information about terrorist groups and their activities.

Crenshaw (1990) [2] argues that because terrorist behaviour cannot be labelled as pathological or irrational due to the lack of empirical evidence to support such notions, it must therefore be considered a choice which is made following a process of logical reasoning. As such terrorist activity can be described as rational and comprehensible in light of the circumstances and contexts in which it occurs. Individual psychological processes toward involvement can be described as rational and logical because of the primarily psychological benefits associated with involvement in terrorism for example, a sense of belonging, status, or power; perceptions of excitement or empowerment. Individual reasons why people become involved are many and varied, with no single catalyst event that explains involvement [3],

Correspondence: Ibowmangrieve@lincoln.ac.uk

School of Psychology, University of Lincoln, Lincoln, UK however research indicates that involvement is a gradual process that occurs over time. This gradual process of becoming involved is mediated by 'group' factors, the social aspects of which provide justifications and support for increasing involvement over time.

Despite the clandestine nature of terrorist movements and their predominant incompatibility with first-hand research our understanding of involvement and recruitment processes has increased in recent years. For example, it has been noted in numerous studies that inter-personal bonds play an important role in this recruitment process. Della Porta (1992) [4] for example, from empirical research with Italian militants, suggests that an important stage in the socialisation process, which leads to involvement in a terrorist or underground movement, is the construction of peer groups during adolescence. Similarly, in a more recent study Post, Sprinzak and Denny (2003) [5], based on semi-structured interviews with incarcerated Middle Eastern terrorists, found that peer influence was cited as a dominant reason for joining a terrorist group. Furthermore recent studies relating to Islamic fundamentalist recruitment indicate that kinship and social bonds also play a key role in this process. Sageman (2004) [6] for example, in an analysis of 400 terrorist biographies, found that sixty-eight percent had pre-existing friendship bonds to others involved in the Jihad or joined the Jihad as a collective decision, while a further twenty percent joined 
through kinship bonds, meaning that the individual had a close relative in the Jihad.

Passy (2000) [7] states that social networks play an important role in influencing the behaviour of the individual and their readiness to take part in collective action because of their inherent functions, such as socialising, recruitment and decision shaping; success or failure in the recruitment process ultimately is dependent on the relationship formed by the recruiter with the potential recruit. According to Starks and Sims Bainbridge (1980) [8] the recruiter must 'bond' with the potential recruit for the process to be successful. The Internet and virtual communities in particular may aid in facilitating this process. For example, Back (2002) [9] draws attention to the use of websites and virtual communities to recruit new members, by providing contact information and details on how to join and contribute to support activities. Encouraging Internet users to become involved in online support activities serve to draw supporters further into the movement. Members can also use virtual communities to make contact with other supporters within their localities, forming both on and offline communities, networks and bonds through the Internet. Arguably the most potent combination will be involvement online and identification with the terrorist group, in addition to exposure to recruiters and opportunities to engage in support behaviours in the physical world.

\section{Case description}

The internet, virtual communities, recruitment \& processes of involvement

While the effectiveness of the bomb remains essential to the terrorist movement in terms of the psychological element of terrorism and to draw attention to the movement and their goals, the Internet provides a safe, easy and cheap means of communicating, disseminating propaganda, gathering intelligence, promoting support, demonising the enemy and raising funds. Terrorist use of the Internet and the communicative value the use of this technology brings, are wide ranging and farreaching. In essence the Internet provides a new solution to the old problem of communication; where once terrorist movements were reliant on 'traditional' forms of media to bring their 'cause' to the public, the Internet now facilitates a broad spectrum of communication possibilities, from websites to virtual communities.

The term 'virtual community' can be used here as an anchor, an already formulated notion of shared online space and communicative interaction between users [10], from which it is possible to examine the content and nature of online communities in support of terrorist movements and extremist ideologies. Virtual communities of this nature have important functions for the individual and the group, providing a 'safe haven' for supporters of extremist ideologies, a forum of validation and support and the means to become knowledgeable and increasingly involved within the movement over time. Analysis and interpretation of online interactions within virtual communities [11] indicate that community interaction may play a role in the earlier phases of the recruitment process particularly those relating to initial support and involvement.

The discourses created and sustained within virtual communities can be used to disseminate information, to communicate ideologies, to promote and propagandise, to encourage involvement and throughout all of these to potentially facilitate the recruitment of individuals to specific groups. The sustenance of discourses that seek to dehumanise the enemy and justify the ideology of the movement contributes to a community of validation that exists for members and potential members of the movement. It can be argued that virtual community members exist in some kind of a pre- or semi-radicalized state; they are groups of members, potential members, recruiters and recruits.

\section{Discussion \& evaluation}

Recruitment online: some examples from the radical right As early as 2001 Ray and March II [12] investigated the use of Internet by white extremists for recruitment purposes. These authors found that white extremist movements were indeed using the services and facilities provided by the Internet to recruit new members and encourage investment and further online involvement in the activities of the organisation. The ease of access to material provided by the Internet has increased the likelihood of both adults and young people searching online to find something to believe in or to reaffirm their already existing beliefs, as such the Internet can be used as a gateway into the particular culture, ideals and beliefs of a movement in question [13]. The following quote from a member of the radical right virtual community of Stormfront illustrates the important role the Internet can play in recruitment and involvement processes - "It was the Internet that got me interested: checking out sites like the Hammerskins and Combat 18/Screwdriver.net in particular. Then after a few emails etc., I got contacts and then was able to meet up with like minded people in the flesh...it all just grew from there. Never underestimate the power of the Internet when it comes to recruiting new folk to our movement."

The availability of White Power music and white supremacist computer games online (made available through websites and virtual communities), are used to target youths specifically in an attempt to interest them in the movement with the aim of recruitment. Similarly 'white' dating services can function effectively in the promotion and sustenance of right wing networking [14]. 


\section{White power music}

The significance of White Power music to the recruitment process involving young people is worthy of mention particularly in light of the many websites that exist to promote such music. The White Power music scene remains one of the fundamental links promoting a wide radical right (in particular neo-Nazi/skinhead) network, with music and lyrics used not only to promote violence against minorities but also to reflect the socio-economic issues and grievances of importance to the movement, such as immigration policies, the 'Jewish conspiracy' and belief in the inevitability of a race war [15]. According to Cotter (1999) [15], the lyrics of such music reinforce the White Power rhetoric and acts as an important recruitment tool; representing primarily the youth sub-culture of the movement.

In the following example a user of the radical right virtual community 'Stormfront' refers to the role of White Power music and the Internet in his involvement process "I was on the Internet one night looking for a song on some file sharing program. I came across one called "White Power" by a band called Skrewdriver. I hated negroes, spics, gays, etc. and decided to download it. The second Ian Stuart shouted out "White Power 1,2,3,4" $i$ was HOOKED." In this case the music downloaded from the Internet lead to this individual 'surfing the net' further to find the website of a White Power record label and subsequently the purchasing of David Duke's book 'My Awakening' which is in turn cited by many individuals as playing an important role in becoming involved in support of the radical right.

\section{Computer games}

The increasing popularity and sophistication of computer games is being utilised by extremist elements online to draw in potential new recruits, targeting primarily the youth demographic [12]. The increasing sophistication of these games and their potential as a propaganda and recruitment tool should not be ignored. For example according to the Anti-Defamation League (2002) [16] Resistance Records (owned by The National Alliance and considered the main distributors of White Power rock), have widened their product base to include racist and anti-Semitic games such as 'Ethnic Cleansing'. This particular game is based on other more mainstream games such as Doom and Quake. It is a city-based game and the player can choose his attire, with KKK robes or Skinhead garb as the options. The player moves through the game murdering 'predatory sub-humans' and their Jewish 'masters' in order to save the white world. Throughout the game National Alliance signs and posters can be seen in the background while White Power rock bands provide the background music. In the final stages of the game the player is confronted by the 'end boss' (Ariel Sharon) who shouts statements such as "We have destroyed your culture", when the Sharon character is killed he says "Filthy white dog, you have destroyed thousands of years of planning" (reflecting the conspiracy theory of the Jews being the Master planners plotting the downfall of the white race) [16]. Ethnic Cleansing is just one of the games promoted and sold by the National Alliance and affiliate Resistance Records. Another game White Law is also for sale from the site and is reminiscent of The Turner Diaries ${ }^{\mathrm{a}}$ (which had been rumoured to be planned for release as a computer game in 2002). The associated blurb for 'White Law' claims, "More weapons, more levels, much more challenging than Ethnic Cleansing". (These games can be purchased for just US\$10 each). While the link between right wing inspired online gaming \& computer gaming in general remains tentative at best it continues to serve an important propaganda dissemination function for Right Wing extremist movements in general [11].

\section{Online dating service - 'Whites Only'}

In relation to the facilitation of interpersonal bonds online, some Radical Right communities (and websites) have set up dating services. Such services target white men and women who desire contact on a personal level, and can have an impact on lifestyle choices for members of the movement making it easier for them to meet a partner with similar political/ideological views. For example, a number of websites are dedicated purely to 'White Pride' dating services, such as euro datelink (www.eurodatelink.com/). The Stormfront discussion forum also provides a forum section dedicated to white singles seeking dates, this section of the board is divided into two subsections, one dedicated to 'talk', the other dedicated to 'dating advice'. These facilities are popular among single users and appear to be well used. They provide information and links to other white dating services, for example this information posted by one of the moderators:

\footnotetext{
"Dating web sites are very popular on the Internet. There are many dating sites for many different ethnic groups -- Jewish, Black, Indian, Native American, Arab, and Asian. However, if you look for White singles, there isn't much. We needed a dedicated dating site for normal White people of European descent who would like to meet people with a similar background. Therefore we decided to launch Eurodatelink.net. Eurodatelink is for people of European descent wherever they may live, rich or poor, Christian, pagan, or atheist who share one common desire: to meet other White people for dating, romance, or friendship. http://www.eurodatelink.net/ is a real dating site for White heterosexual people looking to meet singles or who just want to make new friends."
} 
The use of the Internet, particularly websites and discussion forum services, to promote in-group networking and 'dating' services for whites only, are noteworthy not simply because they represent a means for individuals to meet other like minded individuals but also because they can arguably be seen as facilitating increased involvement. For example, in encouraging others to date within their own race group members promote the ideology of the group as important in relation to life decisions outside of the virtual realm. Similarly, such services provide a way for people to become involved in this movement and to become acquainted with others within the movement on a more personal level. The fostering of personal relationships with others involved within extremist movements has been identified as a contributing factor toward increasing involvement over time. The potential for relationships formed online to contribute to the involvement process of individuals has not been empirically studied and perhaps warrants further investigation, particularly given the large number of Internet and community members who apparently avail of this service.

\section{Conclusions}

The radical right represents a factionalised movement with dispersed networked organisational structure which primarily adheres to the notion of 'leaderless resistance'. While the radical right have not actively orchestrated a large-scale terrorist campaign to achieve their aims they continue to retain an interested body of supporters and promoters, as exemplified by their online presence, in particular sophisticated virtual communities of support with large number of registered members.

Essentially virtual support communities facilitate social interaction and the formation of social bonds, which in turn can lead to changes in attitudes and behaviour over time. These changes in attitude might include adopting the most prevalent ideology expressed within the community. Similarly changes in behaviour might include involvement in a range of both on and off line activities in support of the ideology/organisation. Just as individuals who may be open to supporting an organisation do not necessarily become further involved, so is the case for virtual community members. Although virtual community members may freely express their opinions online, not all of them will take the next step and become new members or recruits (of either the online or offline organisations), similarly not all individuals become increasingly involved.

However given that virtual communities promote discussion, interaction and the formation of interpersonal bonds and relationships, which often occur when individuals use the communities regularly, they are potential recruiting grounds and should be recognised as such. This is particularly the case in light of research that suggests this may be an important factor in the recruitment process [12]. Limited numbers of people decide to become members of terrorist organisations however the Internet has the potential to facilitate at least some level of recruitment. Arguably this will be most apparent where there is a strong online presence that encourages and promotes involvement in support related activities such as donating funds, distributing fliers, supporting Prisoners of War and/or engaging in online support activities (with the potential to later engage in offline support activities). With this in mind it is important to continue investigating how and why terrorist movements and their supporters use the Internet and to consider that these uses are open to innovation and change reflecting the dynamic nature of modern technology.

\section{Endnotes}

${ }^{a}$ The Turner Diaries (1978), written by William Pierce (former leader of the National Alliance) under the pseudonym Andrew Macdonald, provide a blueprint for the organisation and strategic development of a clandestine terrorist group.

\section{Competing interests}

The authors declare that they have no competing interests.

\section{Acknowledgements}

Journal instruction requires an Acknowledgements section however none was provided. In this regard, please provide the missing section. Many thanks to Alison Torn and EISIC reviewers who commented on earlier drafts of this paper.

Received: 22 March 2012 Accepted: 19 February 2013 Published: 23 March 2013

\section{References}

1. N Friedland, Becoming a terrorist: Social and individual antecedents, in Terrorism: Roots, impact, responses, ed. by L Howard (Praeger, New York, 1992), pp. 81-94

2. M Crenshaw, The logic of terrorism: Terrorist behaviour as a product of strategic choice, in Origins of terrorism: Psychologies, ideologies, theologies, states of mind, ed. by W Reich (Cambridge University Press, Cambridge, 1990), pp. 7-24

3. J Horgan, The Psychology of Terrorism (Routledge, Oxon, 2005)

4. Dd Porta, Political socialization in left-wing underground organizations: Biographies of Italian and German militants, in Social movements and violence: Participation in underground organizations, ed. by Dd Porta (JAI Press, Greenwich, CT, 1992), pp. 259-290

5. J Post, E Sprinzak, L Denny, The terrorists in their own words: Interviews with 35 incarcerated Middle Eastern Terrorists. Terrorism \& Political Violence 15(1), 171-184 (2003)

6. M Sageman, Understanding terrorist networks (University of Pennsylvania Press, Philadelphia, 2004)

7. F Passy, Socialization, recruitment, and the structure/agency gap. A specification of the impact of networks on participation in social movements, 2000. Retrieved June 20 th, 2011 from http://www.nd.edu/ $\sim$ dmyers/lomond/passy.pdf

8. R Starks, W Sims Bainbridge, Networks of faith: Interpersonal bonds and recruitment to cults and sects. The American Journal of Sociology 85(6), 1376-1395 (1980)

9. L Back, Aryans reading Adorno: Cyber-culture and twenty-first century Racism. Ethnic \& Racial Studies 25(4), 628-651 (2002)

10. S Jones, Cybersociety: Computer Mediated Communication and Community (Sage Publications, Thousand Oaks, 1995) 
11. L Bowman-Grieve, Exploring Stormfront: The Virtual Community of the Radical Right. Studies in Conflict \& Terrorism 32(11), 989-1007 (2009)

12. B Ray, \& GE Marsh II, Recruitment by extremist groups on the Internet. (Electronic version) First Monday, 6 (2), 2001. Retrieved June 20 ${ }^{\text {th }}, 2011$ from http:/firstmonday.org/htbin/cgiwrap/bin/ojs/index.php/fm/article/view/834/743

13. L Bowman-Grieve, Irish Republicanism and the Internet: Support for new wave dissidents. Perspectives on Terrorism 4(2), 22-34 (2010)

14. R Ezekiel, The racist mind (Viking, New York, 1995)

15. JM Cotter, Sounds of Hate: White Power rock and roll and the Neo-Nazi Skinhead subculture. Terrorism and Political Violence 11(2), 111-140 (1999)

16. Anti-Defamation League. Racist Groups Using Computer Gaming to Promote Violence against Blacks, Latinos and Jews, 2002. Retrieved June 20th, 2011 from http://www.adl.org/videogames/default.asp

doi:10.1186/2190-8532-2-9

Cite this article as: Bowman-Grieve: A psychological perspective on virtual communities supporting terrorist \& extremist ideologies as a tool for recruitment. Security Informatics 2013 2:9.

\section{Submit your manuscript to a SpringerOpen ${ }^{\circ}$} journal and benefit from:

- Convenient online submission

- Rigorous peer review

- Immediate publication on acceptance

- Open access: articles freely available online

- High visibility within the field

- Retaining the copyright to your article 